\title{
Effect of Flux Addition Method on Hot Metal Desulfurization by Mechanical Stirring Process
}

\author{
Yoshie NAKAI, ${ }^{1{ }^{* *}}$ Yuta HINO, ${ }^{2)}$ Ikuhiro SUMI, ${ }^{3)}$ Naoki KIKUCHI, ${ }^{1)}$ Yuichi UCHIDA ${ }^{1)}$ and Yuji MIKI ${ }^{1)}$ \\ 1) Steelmaking Research Department, Steel Research Laboratory, JFE Steel Corporation, 1 Kokan-cho, Fukuyama, $721-8510$ \\ Japan. $\quad 2$ S) Slag and Refractories Department, Steel Research Laboratory, JFE Steel Corporation, 1 Kawasaki-cho, Chuo- \\ ku, Chiba, 260-0835 Japan. $\quad 3)$ Environmental Process Research Department, Steel Research Laboratory, JFE Steel \\ Corporation, 1-1 Minamiwatarida-cho, Kawasaki-ku, Kawasaki, 210-0855 Japan.
}

\author{
(Received on November 25, 2014; accepted on March 16, 2015; originally published in Tetsu-to- \\ Hagané, Vol. 101, 2015, No. 1, pp. 1-10)
}

\begin{abstract}
The effects of three flux addition methods on hot metal desulfurization with mechanical stirring were investigated in a 1/12-water model test and a $70 \mathrm{~kg}$ hot metal desulfurization test. The flux addition methods studied here were top addition on the bath surface in the first period of desulfurization (batch addition), continuous addition from the top, and powder blasting with nitrogen gas. The desulfurization rate when powder blasting is applied is larger than that of either continuous addition or batch addition. The obtained aggregated slag (desulfurization flux) particle diameters after desulfurization were $0.76 \mathrm{~mm}$ (batch addition) and $0.38-0.44 \mathrm{~mm}$ (powder blasting). Desulfurization behavior was analyzed assuming that the interfacial area between the flux and the hot metal is proportional to the estimated size of the aggregated slag. Based on this analysis, the effect of powder blasting with nitrogen gas on improvement of desulfurization efficiency was interpreted to be the combined result of a) promotion of flux dispersion and avoiding aggregation during flux addition and b) prevention of slag particle aggregation in the hot metal during stirring.
\end{abstract}

KEY WORDS: hot metal; desulfurization; mechanical stirring; powder blasting.

\section{Introduction}

In recent years, lowering the sulfur content of hot metal in the stage of hot metal pretreatment has become important for meeting demand for high purity steels for applications such as thick plates for construction and shipbuilding and linepipe for transportation of oil and natural gas. The properties required in those materials include ductility, low-temperature toughness, weldability, and resistance to hydrogen-induced cracking.

Sulfide inclusions are known to affect the properties of steel materials. For example, MnS elongates in the hotrolling process and increases the anisotropy of the steel product or acts as a starting point for rust under corrosive environments. For high purity steel, a sulfur content of $<0.001 \mathrm{mass} \%$ is indispensable.

One countermeasure for achieving even lower sulfur contents than in the past is hot metal desulfurization. In particular, a mechanical stirring method employing a rotating impeller was industrialized and is used in many companies to obtain high desulfurization efficiency.

Several hot metal desulfurization methods with mechanical stirring are known, for example, the Demag-Ostberg (DORA) method ${ }^{1)}$ developed in 1966 and the Rheinstahl

\footnotetext{
* Corresponding author: E-mail: y-nakai@jfe-steel.co.jp DOI: http://dx.doi.org/10.2355/isijinternational.55.1398
}

method $^{2)}$ developed in 1968.

In Japan, Kanbara et al. ${ }^{3)}$ succeeded in performing sulfur removal to $<0.003$ mass $\%$ by the KR method.

With respect to desulfurization flux, many investigations have been reported ${ }^{4-7)}$ techniques for increasing the desulfurization efficiency of the flux in hot metal by mechanical stirring. However, higher reaction efficiency is required from the viewpoint of reducing desulfurization flux consumption/slag generation.

For improvement of desulfurization efficiency in hot metal desulfurization, it is important to increase the interfacial area of reaction. Based on an investigation of the flux dispersion behavior in hot metal desulfurization with mechanical stirring, the authors reported that both enhancing particle dispersion and avoiding particle aggregation are important for improving desulfurization efficiency. ${ }^{8,9)}$

However, reducing the diameter of desulfurization flux to increase the interfacial area results in increased scattering of the flux during flux addition. As methods for adding fine flux to hot metal while preventing flux scattering, injection from the lance or bottom blowing tuyere and powder blasting from a top lance can be considered. Although powder injection requires complicated equipment, powder blasting can be realized with simple equipment.

In this work, the effects of three flux addition methods (batch, continuous, blasting) on hot metal desulfurization with mechanical stirring were investigated in a $1 / 12$-water 
model experiment and $70 \mathrm{~kg}$ hot metal desulfurization experiments.

The water model was used to investigate flux dispersion and aggregation behavior during flux addition with impeller stirring. The $70 \mathrm{~kg}$-scale hot metal experiments with mechanical stirring were then performed in order to investigate the influence of the respective flux addition methods on the desulfurization reaction.

In addition, the size of aggregated slag was estimated using an aggregation model based on granulation theory in order to compare flux aggregation behavior, and the mechanism responsible for increasing desulfurization efficiency depending on the flux addition method was also considered.

\section{Water Model Experiment}

\subsection{Experimental Procedure}

Flux dispersion/aggregation behavior with impeller stirring was investigated from the physical point of view by using a water model. A schematic diagram of the 1/12-scale water model apparatus is shown in Fig. 1. Table 1 summarizes the experimental conditions used in the water model experiment.

The apparatus consists of a cylindrical acrylic tank (inner diameter: $350 \mathrm{~mm}$, height: $610 \mathrm{~mm}$ ) and a carbon impeller (diameter: $160 \mathrm{~mm}$, height: $50 \mathrm{~mm}$, and impeller width: 25 $\mathrm{mm}$ (4 blades, angle of blades to horizontal plane: $90^{\circ}$ )). Although the rotation speed of the impeller can be controlled by an inverter, in this experiment, the rotation speed was fixed at $275 \mathrm{rpm}$. The depth of the water bath was 280 $\mathrm{mm}$. The impeller immersion depth, defined as the distance from the water surface to the bottom level of the impeller, was set at $120 \mathrm{~mm}$. Teflon particles, which have poor wettability with water $(0.36 \mathrm{~kg} / \mathrm{ch}$, average diameter: $0.12 \mathrm{~mm}$, density: $30 \mathrm{~kg} / \mathrm{m}^{3}$ ) were added on the water as a model flux. Teflon particles were selected to satisfy the condition that the ratio of buoyancy to surface tension and the Weber number We (ratio of force of inertia to surface tension) should be similar to that in the hot model experiment (water model: $\mathrm{We}=4.3 \times 10^{4}$, hot model: $\mathrm{We}=5.6 \times 10^{4}$ ).

The nitrogen gas flow rate in powder blasting was determined so that the pressure of the gas at the surface of the liquid was the same in this water model experiment and in the hot metal desulfurization experiment. The amount of particles was determined so that the volume ratio of particles and water in this water model experiment and that of the desulfurization flux and hot metal in the hot metal desulfurization experiment was the same.

In this study, the following flux addition methods were employed: (1) Batch addition, in which flux was added on the bath surface from the top in the first period of desulfurization, and the flux addition time was 5 seconds. (2) Continuous addition, in which flux was added continuously from the top. (3) Powder blasting, in which flux was blasted from a lance with nitrogen gas.

In continuous addition and powder blasting, the flux addition rate was $0.06 \mathrm{~kg} / \mathrm{min}$. Flux dispersion/aggregation behavior was observed and analyzed using a video camera.

\subsection{Experimental Results}

The particle dispersion behaviors after flux addition in the

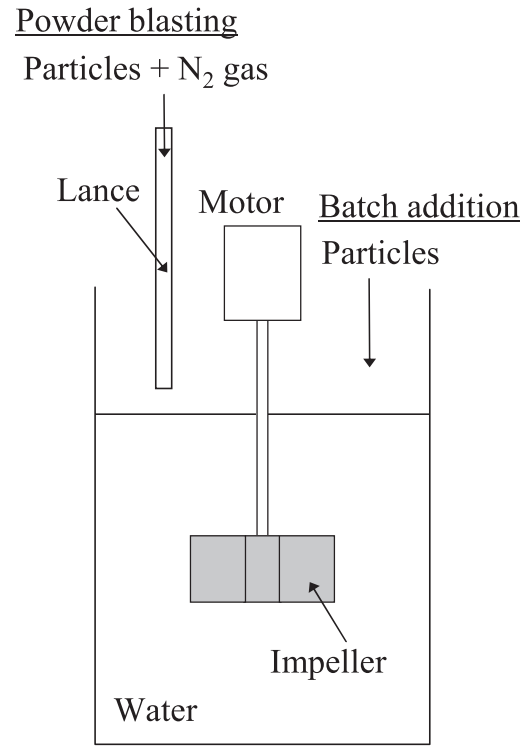

Fig. 1. Schematic diagram of apparatus for water model experiment.

Table 1. Experimental conditions for water model experiment.

\begin{tabular}{|c|c|c|}
\hline \multirow{2}{*}{ Vessel } & Height & $610 \mathrm{~mm}$ \\
\hline & Diameter & $350 \mathrm{~mm}$ \\
\hline \multirow[t]{3}{*}{ Water } & Depth & $280 \mathrm{~mm}$ \\
\hline & Height & $50 \mathrm{~mm}$ \\
\hline & Diameter & $160 \mathrm{~mm}$ \\
\hline \multirow[t]{3}{*}{ Impeller } & Width & $25 \mathrm{~mm}$ \\
\hline & Rotation speed & $275 \mathrm{rpm}$ \\
\hline & Immersion depth & $120 \mathrm{~mm}$ \\
\hline \multicolumn{2}{|c|}{ Flux addition method } & $\begin{array}{l}\text { (1) Batch addition } \\
\text { (2) Continuous addition } \\
\text { (3) Powder blasting }\end{array}$ \\
\hline $\begin{array}{l}\text { Continuous addition } \\
\text { conditions }\end{array}$ & Addition rate & $0.06 \mathrm{~kg} / \mathrm{min}$ \\
\hline \multirow{3}{*}{$\begin{array}{l}\text { Powder blasting } \\
\text { conditions }\end{array}$} & Addition rate & $0.06 \mathrm{~kg} / \mathrm{min}$ \\
\hline & Gas flow rate & $75 \mathrm{Nl} / \mathrm{min}$. \\
\hline & Lance height & $50 \mathrm{~mm}$ \\
\hline \multirow{3}{*}{ Particle conditions } & Diameter & $\phi 0.12 \mathrm{~mm}$ \\
\hline & Density & $30 \mathrm{~kg} / \mathrm{m}^{3}$ \\
\hline & Amount of particles & $0.36 \mathrm{~kg} / \mathrm{ch}$ \\
\hline
\end{tabular}

water model experiment are shown in Fig. 2. In the case of batch addition, flux aggregation was observed on the water surface, and the aggregated flux was then drawn inward toward the impeller center, as shown in Fig. 2(a).

In continuous addition, although aggregation was not as remarkable as in batch addition, some particles aggregated at the water surface after stirring was stopped.

In contrast, little aggregation was observed in powder blasting, and the flux particles penetrated directly into the water.

In batch addition, the diameter of the aggregated particles was large, and the large aggregated particles rotated in the water as shown in Fig. 2(b).

In continuous addition, the diameter of the aggregated 

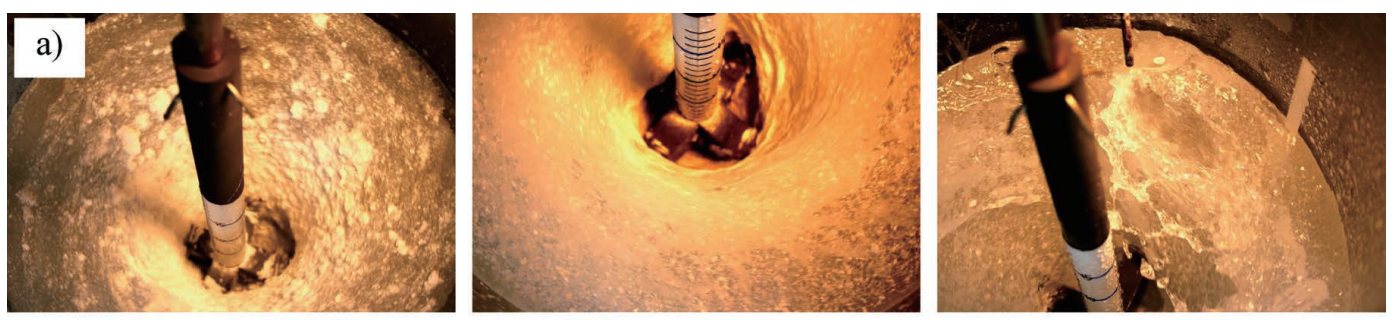

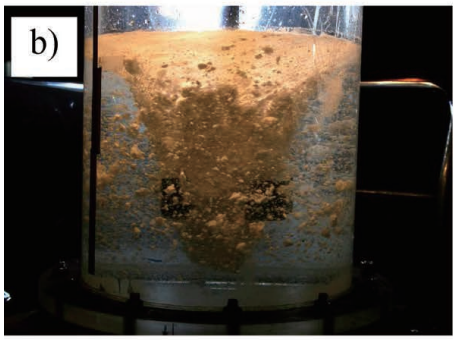

Batch addition

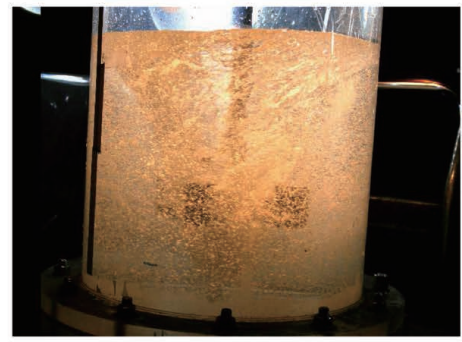

Continuous addition

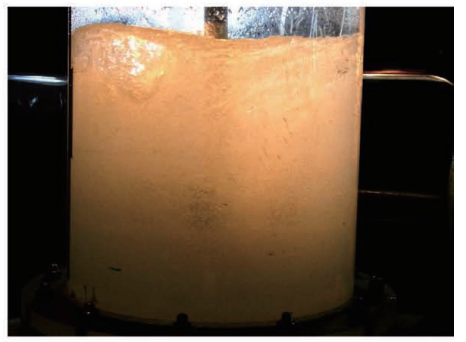

Powder blasting addition

Fig. 2. Particle dispersion behaviors after flux addition in water model experiment: a) Surface of water, b) Side view.

particles was smaller than that in batch addition. In powder blasting, the diameter of the aggregated particles was the smallest among the three methods, and the water was cloudy due to the dispersion of the flux during rotation.

Based on the water model experiment, it is thought that flux aggregation takes place when flux is entrained from the water surface into the water bath. Under the powder blasting condition, the flux particles penetrate directly into water, so particle aggregation at the water surface is minimal, and the diameter of the aggregated particles in the water is relatively small.

\section{Hot Metal Experiments}

\subsection{Experimental Procedure}

In order to investigate the influence of the flux addition method on the desulfurization reaction, $70 \mathrm{~kg}$-scale hot metal experiments with mechanical stirring were carried out. The experimental apparatus and conditions are shown in Fig. 3 and Table 2, respectively.

A high frequency induction furnace was used to prepare the hot metal. $70 \mathrm{~kg}$ of hot metal (4-5 mass $\% \mathrm{C}-0.04$ mass $\% \mathrm{~S}$ ) was melted in a magnesia crucible (inner diameter: $250 \mathrm{~mm}$, depth: $500 \mathrm{~mm}$ depth), and the temperature was set at $1573 \mathrm{~K}$. The hot metal was stirred by a carbon impeller (4 blades, diameter: $100 \mathrm{~mm}$, height: $50 \mathrm{~mm}$ ), which was immersed in the hot metal and rotated at $450 \mathrm{rpm}$. The impeller immersion depth was defined in the same manner as in the water model experiment, and was fixed at $150 \mathrm{~mm}$. After achieving a fixed rotation speed, aluminum granules were added as a deoxidant, and a fine $\mathrm{CaO}$ flux (maximum size $\leqq 250 \mu \mathrm{m}$, average size $=100 \mu \mathrm{m}$ ) was added. The flux consumption was $5 \mathrm{~kg} / \mathrm{t}$, and the experimental time was 20 minutes. Hot metal samples were taken at predetermined intervals during the experiment.

Slag samples consisting of all of the slag after the experiment were taken from the crucible, and their size distributions were measured in order to evaluate the average particle diameter of the slag. The slag samples were screened and separated into 11 size classes: $\leqq 0.5 \mathrm{~mm}, 0.5-1.0 \mathrm{~mm}, 1.0$ $2.8 \mathrm{~mm}, 2.8-4.0 \mathrm{~mm}, 4.0-4.75 \mathrm{~mm}, 4.75-5.6 \mathrm{~mm}, 5.6-6.3$

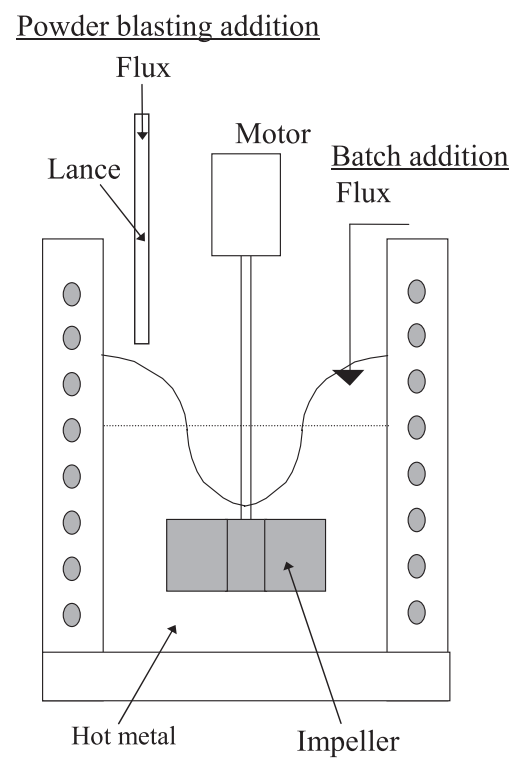

Fig. 3. Schematic diagram of apparatus for $70 \mathrm{~kg}$-scale hot metal experiments.

Table 2. Experimental conditions for $70 \mathrm{~kg}$-scale hot metal experiments.

\begin{tabular}{|c|c|c|}
\hline \multicolumn{2}{|c|}{ Furnace } & $\begin{array}{l}150 \mathrm{~kg} \mathrm{IF} \\
\phi 250 \mathrm{~mm}\end{array}$ \\
\hline \multirow{3}{*}{ Metal } & $\begin{array}{l}\text { Chemical } \\
\text { composition }\end{array}$ & $\begin{array}{c}\mathrm{Fe}-4 \sim 5 \text { mass } \%[\mathrm{C}] \\
-0.04 \text { mass } \%[\mathrm{~S}]\end{array}$ \\
\hline & Weight & $70 \mathrm{~kg}$ \\
\hline & Depth & $204 \mathrm{~mm}$ \\
\hline \multicolumn{2}{|c|}{ Rotation speed } & $700 \mathrm{rpm}$ \\
\hline \multirow{3}{*}{$\begin{array}{c}\text { Impeller } \\
\text { dimensions }\end{array}$} & Height & $50 \mathrm{~mm}$ \\
\hline & Diameter & $100 \mathrm{~mm}$ \\
\hline & Width & $25 \mathrm{~mm}$ \\
\hline \multicolumn{2}{|c|}{ Impeller immersion depth } & $150 \mathrm{~mm}$ \\
\hline \multicolumn{2}{|c|}{ Temperature } & $1573 \mathrm{~K}$ \\
\hline \multirow{3}{*}{\multicolumn{2}{|c|}{ Flux }} & $\mathrm{CaO}, \leqq 250 \mu \mathrm{m}$ \\
\hline & & $5 \mathrm{~kg} / \mathrm{t}$ \\
\hline & & $\mathrm{Al}(0.3 \mathrm{~kg} / \mathrm{t})$ \\
\hline
\end{tabular}


Table 3. Conditions of flux addition in $70 \mathrm{~kg}$-scale hot metal experiments.

\begin{tabular}{|c|c|c|c|}
\hline No. & $\begin{array}{l}\text { Flux Addition } \\
\text { method }\end{array}$ & $\begin{array}{l}\text { Addition } \\
\text { time }\end{array}$ & $\begin{array}{c}\text { Powder blasting } \\
\text { gas flow rate }\end{array}$ \\
\hline A & Batch & $5 \mathrm{~s}$. & - \\
\hline B & Continuous & \multirow{3}{*}{$10 \mathrm{~min}$} & - \\
\hline $\mathrm{C}$ & \multirow{3}{*}{ Powder blasting } & & $200 \mathrm{Nl} / \mathrm{min}$. \\
\hline $\mathrm{D}$ & & & $100 \mathrm{Nl} / \mathrm{min}$ \\
\hline $\mathrm{E}$ & & $3 \mathrm{~min}$. & $200 \mathrm{Nl} / \mathrm{min}$. \\
\hline
\end{tabular}

$\mathrm{mm}, 6.3-8.0 \mathrm{~mm}, 8.0-9.5 \mathrm{~mm}, 9.5-11.2 \mathrm{~mm}$, and $\geqq 11.2$ $\mathrm{mm}$. The average size $D s$ was obtained from Eq. (1). ${ }^{10)}$

$$
D_{a}=\frac{\sum_{i}\left(w_{i}\right)}{\sum_{i}\left(w_{i} / d_{i}\right)}
$$

Where, $d_{i}$ is the average size in each screen size classification $(\mathrm{mm})$, and $w_{i}$ is the total weight of slag for each size classification $(\mathrm{kg})$. The subscript $i$ denotes the screen size classification (1-11). There were no particles of the screen size over $11.2 \mathrm{~mm}$.

The experimental conditions are shown in Table 3. As in the water model experiment, the following flux addition methods were employed: (1) Batch addition, (2) continuous addition, and (3) powder blasting. The flux addition time was 5 seconds in batch addition and 10 minutes in continuous addition.

In powder blasting, the flux was supplied to the hot metal surface with nitrogen gas through a SUS pipe $(\phi 4 \mathrm{~mm})$. The flux addition time was 3 or $10 \mathrm{~min}$ from the beginning of flux addition. Since the amount of flux was constant at 5 $\mathrm{kg} / \mathrm{t}$, the flux addition rates at these addition times were 0.5 and $1.67 \mathrm{~kg} / \mathrm{min} / \mathrm{t}$, respectively. The nitrogen gas flow rates in powder blasting were 100 and $200 \mathrm{Nl} / \mathrm{min}$. The distance from the tip of the powder blasting lance to the surface of the hot metal was $10 \mathrm{~mm}$.

\subsection{Experimental Results}

\subsubsection{Desulfurization Behaviors}

The changes of the sulfur content in the hot metal [S] and the ratio $[\mathrm{S}] /[\mathrm{S}]_{\mathrm{i}}$ (where $[\mathrm{S}]_{\mathrm{i}}$ : initial $[\mathrm{S}]$ ) as a function of time (conditions A, B, and C) are shown in Figs. 4 and $\mathbf{5}$, respectively. The desulfurization rate was large in the order of $\mathrm{C}$ : powder blasting $>\mathrm{B}$ : continuous addition $>\mathrm{A}$ : batch addition. In Fig. 5, the desulfurization rate at experimental times from 0 to 12 min was remarkably different among the experiments with $\mathrm{A}, \mathrm{B}$, and $\mathrm{C}$.

Figures 6 and 7 show respectively the changes of [S] and $[\mathrm{S}] /[\mathrm{S}]_{\mathrm{i}}$ as a function of time under conditions $\mathrm{C}, \mathrm{D}$ and $\mathrm{E}$, that is, under different powder blasting conditions.

In Fig. 7, the desulfurization rate during flux addition was the largest in the case of powder blasting for $3 \mathrm{~min}$, although the desulfurization rate after flux addition had stagnated. When measured at the same powder blasting time of 10 min, there were few increases in the desulfurization rate in condition $\mathrm{D}$. As the nitrogen gas flow rate was small under condition $\mathrm{D}$, this may be due to the influence of the nitrogen gas flow rate for powder blasting.

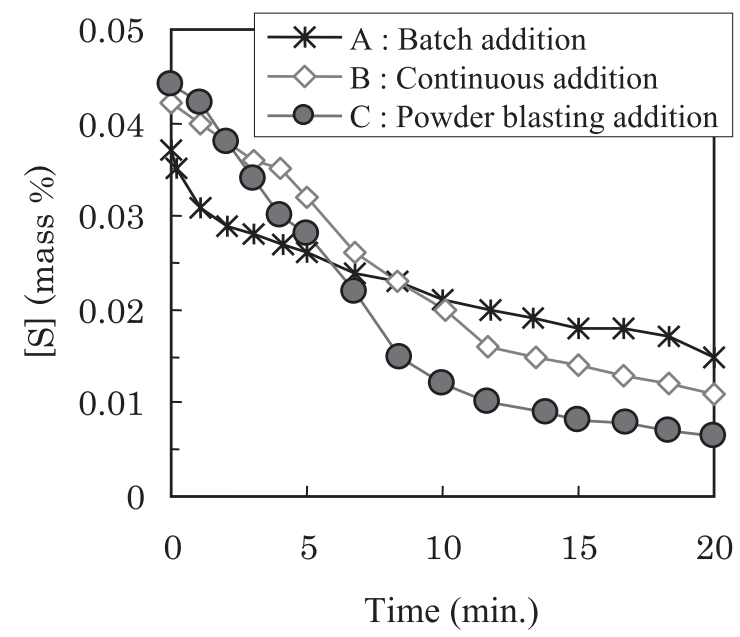

Fig. 4. Desulfurization behaviors in hot metal experiments (conditions $\mathrm{A}, \mathrm{B}$, and $\mathrm{C}$ ).

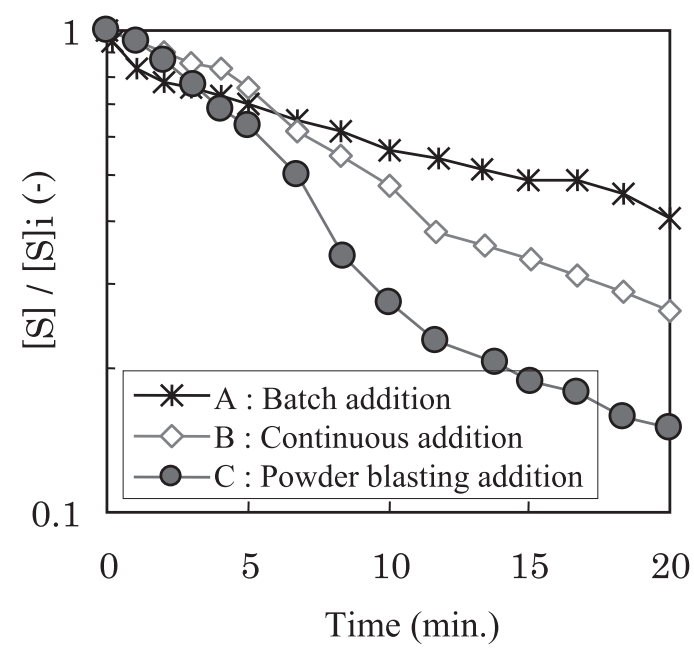

Fig. 5. Changes of $[\mathrm{S}] /[\mathrm{S}]_{\mathrm{i}}$ in hot metal experiments (conditions $\mathrm{A}, \mathrm{B}$, and $\mathrm{C}$ ).

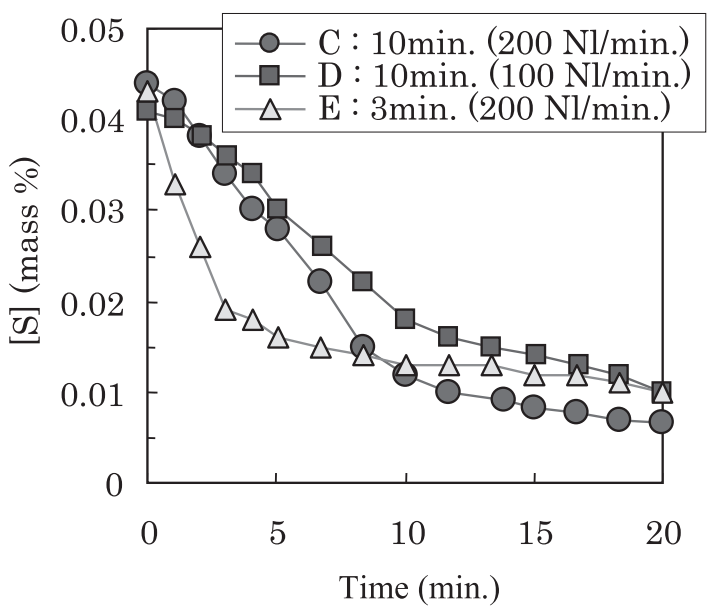

Fig. 6. Desulfurization behaviors in hot metal experiments (conditions $\mathrm{C}$, D, and $\mathrm{E}$ ).

\subsubsection{Change of Aggregated Slag Size}

Slag samples after desulfurization treatment $(20 \mathrm{~min})$ were taken in whole and their size distributions were measured in order to evaluate the average particle diameter of the slag after treatment. An example of the appearance of 


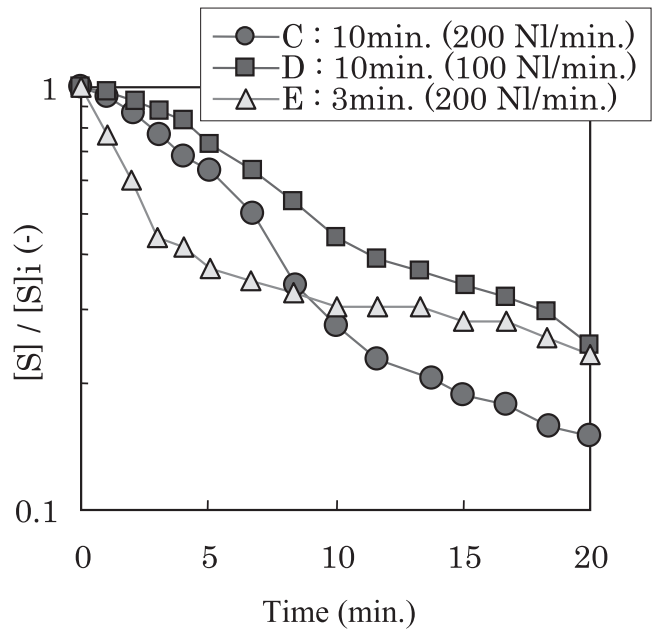

Fig. 7. Changes of $[\mathrm{S}] /[\mathrm{S}]_{\mathrm{i}}$ in hot metal experiments (conditions $\mathrm{C}$, $\mathrm{D}$, and $\mathrm{E})$.

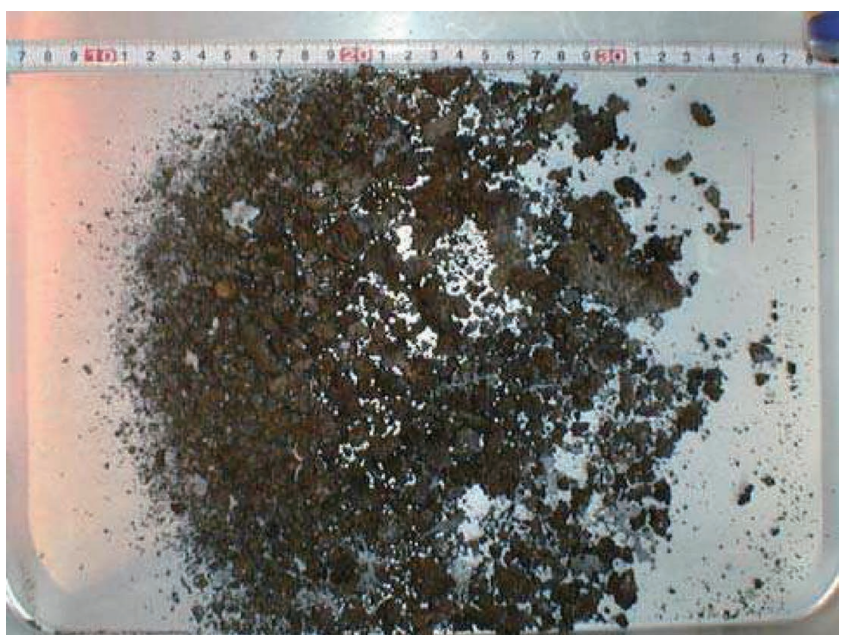

Fig. 8. Photograph of appearance of desulfurization slag after treatment (condition A).

the slag after desulfurization treatment is shown in Fig. 8 (condition A, batch addition, flux consumption: $5 \mathrm{~kg} / \mathrm{t}$ ). Although the average size of the initial flux was $250 \mu \mathrm{m}$ or less, many large slag particles with particle diameters of $1.0-15 \mathrm{~mm}$ were observed after treatment.

Figure 9 shows the slag size distribution after treatment under conditions $\mathrm{A}, \mathrm{B}$, and $\mathrm{C}$. The ratio of slag of $1 \mathrm{~mm}$ or less was high under conditions $\mathrm{B}$ (continuous addition) and $\mathrm{C}$ (powder blasting) compared with condition A (batch addition).

The calculated average particle diameters of the slag after treatment are summarized in Fig. 10. The average particle diameter in condition A (batch addition) is $0.76 \mathrm{~mm}$. The average particle diameters of the slag after treatment in condition B (continuous addition) and $\mathrm{C}, \mathrm{D}$, and $\mathrm{E}$ (powder blasting) are smaller than that in condition A (batch addition). Although the average particle diameter in condition $\mathrm{B}$ (continuous addition) and $\mathrm{C}$ (powder blasting) is similar, the desulfurization behavior, especially the desulfurization rate from flux addition to $10 \mathrm{~min}$, and the final [S] are different, as shown in Fig. 10. Therefore, the difference in the desulfurization behavior under conditions $\mathrm{B}$ and $\mathrm{C}$ cannot be explained only by the particle diameter. Since the influence of the flux addition method is a conceivable factor, this was

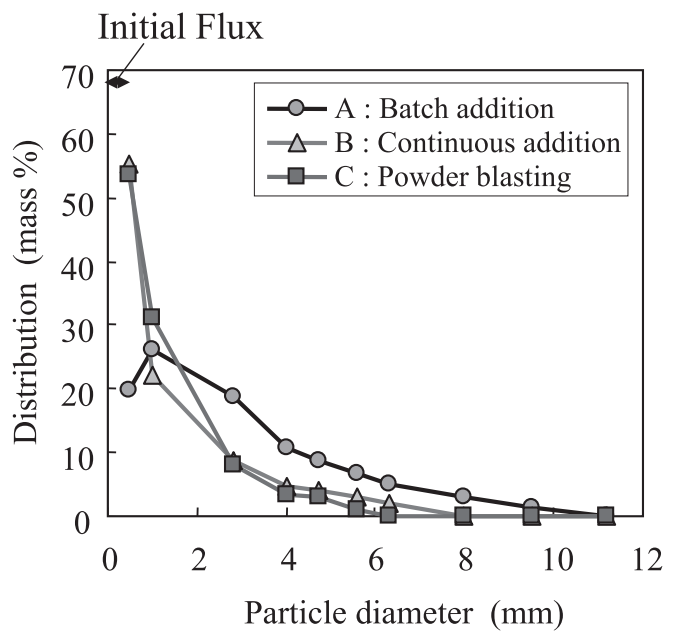

Fig. 9. Changes of particle size distribution in hot metal experiments (conditions A, B, and C).

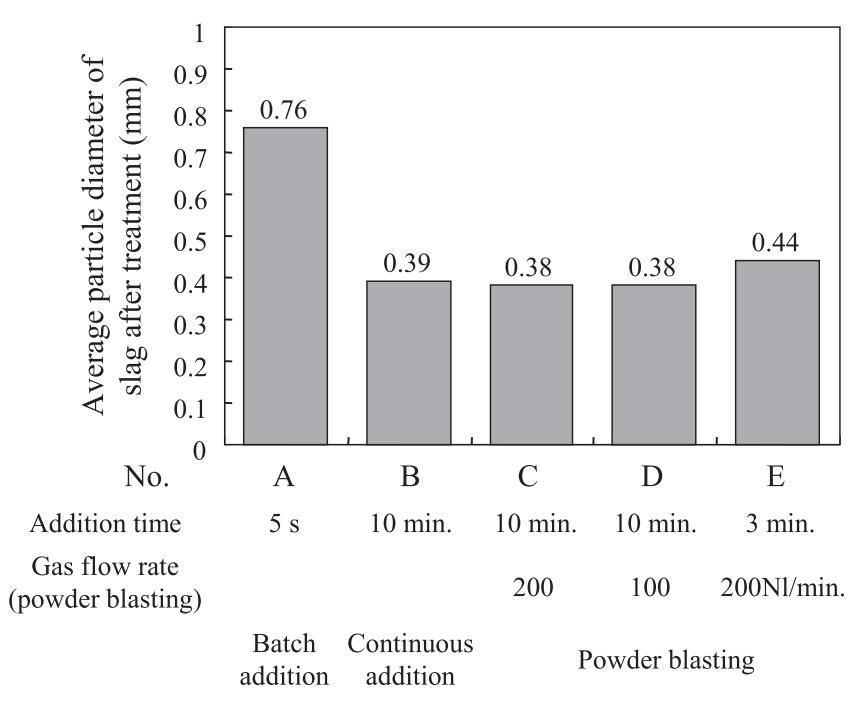

Fig. 10. Average particle diameters of slag after treatment.

investigated by presuming the aggregation behavior after flux addition and evaluating the interfacial area.

\section{Discussion}

\subsection{Aggregation Model}

A difference in the aggregation behaviors may possibly affect desulfurization behavior, even if the particle diameter of the slag after treatment is the same. Therefore, the flux aggregation behaviors with the different flux addition methods were evaluated using the flux aggregation model presented in a previous paper. ${ }^{9)}$

The dispersion and aggregation of particles in a liquid can be expressed by the function of potential energy and the distance between the particles based on their probability of collision. ${ }^{11)}$ The aggregation behavior of monodispersed particles can be expressed by Eq. (2). ${ }^{14)}$

$$
\frac{d \gamma}{d t}=k_{a} \cdot\left(\gamma-\gamma_{e}\right)^{2}
$$

Where, $\gamma$ is the number of particles in a unit volume of liquid $(-), \gamma_{e}$ is the number of particles in the equilibrium state $(-), k_{a}$ is an aggregation rate constant $\left(\mathrm{m}^{3} / \mathrm{s}\right)$, and $t$ is time (second). 
Equation (3) can be given by integrating Eq. (2) assuming $\gamma=\gamma_{f}$, at $t=0$.

Where, $\gamma_{f}$ is the initial number of particles $(-)$.

$$
\gamma=\gamma_{e}+\frac{1}{k_{a} \cdot t+\frac{1}{\left(\gamma_{f}-\gamma_{e}\right)}}
$$

Takenaka et al. ${ }^{12)}$ proposed Eq. (4) based on the granulation rate of spherical particles in a wet condition.

$$
\gamma=\frac{W_{f}}{\frac{\sum(\pi / 6) \cdot D^{3} \rho_{f}(1-\varepsilon)^{n}}{\sum n}} \times \frac{1}{V_{m}}
$$

Where, $n$ is the number of particles with diameter $D, W_{f}$ is the total weight of granulates $(\mathrm{kg}), V_{m}$ is the volume of a particle-dispersed liquid $\left(\mathrm{m}^{3}\right), \varepsilon$ is the void ratio in the aggregated particles $(-)$ and $\rho_{f}$ is particle density $\left(\mathrm{kg} / \mathrm{m}^{3}\right)$.

Equation (5) can be obtained from Eq. (4) by assuming that the particles are spherical. The number of particles in the equilibrium state, $\gamma_{e}$, and the initial particle number, $\gamma_{f}$, can be expressed as Eqs. (6) and (7), respectively.

$$
\begin{gathered}
\gamma=\frac{W_{f}}{(\pi / 6) \cdot D^{3} \rho_{f}(1-\varepsilon)} \times \frac{1}{V_{m}} \\
\gamma_{e}=\frac{W_{f}}{(\pi / 6) \cdot D_{e}^{3} \rho_{f}(1-\varepsilon)} \times \frac{1}{V_{m}} \\
\gamma_{f}=\frac{W_{f}}{(\pi / 6) \cdot D_{f}^{3} \rho_{f}(1-\varepsilon)} \times \frac{1}{V_{m}}
\end{gathered}
$$

Where, $D_{f}$ is the initial particle diameter (flux diameter) (m) and $D_{e}$ is the aggregated particle diameter in the equilibrium state $(\mathrm{m})$.

Furthermore, in continuous addition of flux, both the aggregated flux and the newly-added flux will contribute to a reaction. The newly-added particle number at time $t$, $\gamma_{f n e w(t)}$, can be expressed as Eq. (8). The initial particle number at time t, $\gamma_{f(t)}$, can be expressed as Eq. (9) as the sum of the aggregated particle number at time $\mathrm{t}, \gamma_{(t-1)}$, and $\gamma_{\text {fnew }(t)}$.

$$
\begin{aligned}
& \gamma_{\text {fnew }(t)}=\frac{W_{\text {fnew }(t)}}{(\pi / 6) \cdot D_{f}^{3} \rho_{f}(1-\varepsilon)} \times \frac{1}{V_{m}} \\
& \gamma_{f(t)}=\gamma_{(t-1)}+\gamma_{\text {fnew }(t)}
\end{aligned}
$$

Therefore, the particle number at time $\mathrm{t}, \gamma_{(t)}$, is expressed by Eq. (10) based on Eq. (3).

$$
\begin{aligned}
\gamma_{(t)} & =\gamma_{f(t-1)}+\gamma_{\text {fnew }(t)} \\
& =\gamma_{e}+\frac{1}{k_{a} \cdot t+\frac{1}{\left(\gamma_{f(t-1)}-\gamma_{e}\right)}}+\gamma_{\text {fnew }(t)} \ldots \ldots \ldots . . .
\end{aligned}
$$

Where, $\gamma_{\text {fnew }(t)}$ is the number of newly-added particles at time $\mathrm{t}$ in a unit volume of liquid (-), $W_{\text {fnew }(t)}$ is the total weight of newly-added particles at time $\mathrm{t}(\mathrm{kg}), \gamma_{f(t)}$ is the initial particle number at time $\mathrm{t}(-)$, and $\gamma_{(t)}$ is the particle number at time $\mathrm{t}(-)$.

The aggregated particle diameter in the equilibrium state $D_{e}$ depends on the force balance of the aggregation force between particles and external destructive force. In this work, desulfurization particles in hot metal may aggregate under a force balance between compressive forces such as sintering, and the shear stress caused by mechanical stirring. It is assumed that the force balance acting on the aggregated desulfurization particles in hot metal can be treated by the following procedure. Capes et al. ${ }^{13)}$ proposed that the abovementioned force balance is proportional to both the compressive pressure of the aggregated body and the centrifugal force generated by stirring. Newwitt et al. ${ }^{14)}$ proposed Eq. (11) as the force balance between compressive strength and centrifugal force. Equation (12) can give the aggregated particle diameter in the equilibrium state $D_{e}$.

$$
\begin{gathered}
K\left(\frac{1-\varepsilon}{\varepsilon}\right) \frac{\tau}{D_{f}} D_{e}{ }^{2}=\frac{4}{3} \rho_{f}(1-\varepsilon) \pi \cdot\left(\frac{D_{e}}{2}\right)^{3} \cdot r \omega^{2} \ldots \\
D_{e}=\frac{6 K}{\pi \rho_{f}(1-\varepsilon) r \omega^{2}}\left(\frac{1-\varepsilon}{\varepsilon}\right) \frac{\tau}{D_{f}} \ldots \ldots \ldots \ldots . . .
\end{gathered}
$$

Where, $K$ is a constant depending on the condition of aggregation $(-), \tau$ is interfacial tension between a particle and hot metal $(\mathrm{N} / \mathrm{m}), r$ is radial position $(\mathrm{m})$ and $\omega$ is angular velocity $(\mathrm{rad} / \mathrm{s})$.

From Eq. (11), the value of $K$ was calculated as 0.0598 for the slag diameter of $1.75 \mathrm{~mm}$ obtained by a desulfurization experiment under conditions of a rotation speed of 700 rpm and stirring time of 30 minutes.

The aggregated particle size at time $t, D_{t}$, can be expressed by Eq. (13) based on Eq. (5).

$$
D_{(t)}=\left\{\frac{W_{f(t)}}{(\pi / 6) \cdot \rho_{f}(1-\varepsilon)} \times \frac{1}{V_{m}} \cdot \frac{1}{\gamma_{(t)}}\right\}^{\frac{1}{3}}
$$

If Eq. (10) is substituted for $\gamma_{(t)}$ in Eqs. (13), (14) can be obtained as follows.

$$
D_{(t)}=\left\{\frac{W_{f(t)}}{(\pi / 6) \cdot \rho_{f}(1-\varepsilon)} \times \frac{1}{V_{m}} \cdot \frac{1}{\gamma_{e}+\frac{1}{k_{a} \cdot t+\frac{1}{\left(\gamma_{f(t-1)}-\gamma_{e}\right)}}+\gamma_{\text {fnew }(t)}}\right\}^{\frac{1}{3}}
$$

Where, $W_{f(t)}$ is the total weight of flux which is added during time $\mathrm{t}(\mathrm{kg})$.

Equations (8) and (9) are substituted for $\gamma_{f n e w(t)}$ and $\gamma_{f(t-1)}$ in Eq. (14). $\gamma_{e}$ was calculated with Eq. (6). Under the present experimental conditions, $W_{f}, V_{m}$, and $D_{f}$ are $0.35 \mathrm{~kg}, 0.01$ $\mathrm{m}^{3}$, and $1.0 \times 10^{-4} \mathrm{~m}$ (the initial average particle diameter of the flux), respectively. $\varepsilon$ is 0.567 at the flux density of 3000 $\mathrm{kg} / \mathrm{m}^{3}$ and bulk density of $1300 \mathrm{~kg} / \mathrm{m}^{3}$ in other experimental results. ${ }^{15)}$

$k_{a}$ was obtained by fitting the measured aggregated diameter under various conditions. The values of $k_{a}$ are summarized in Table 4. Figure 11 shows the relationship between the calculated aggregated diameter and measured values.

From Table 4, in continuous addition and powder blasting, the aggregation rate constants are low compared with that in batch addition, showing that aggregation of particles is difficult under the former conditions. The aggregation rate 


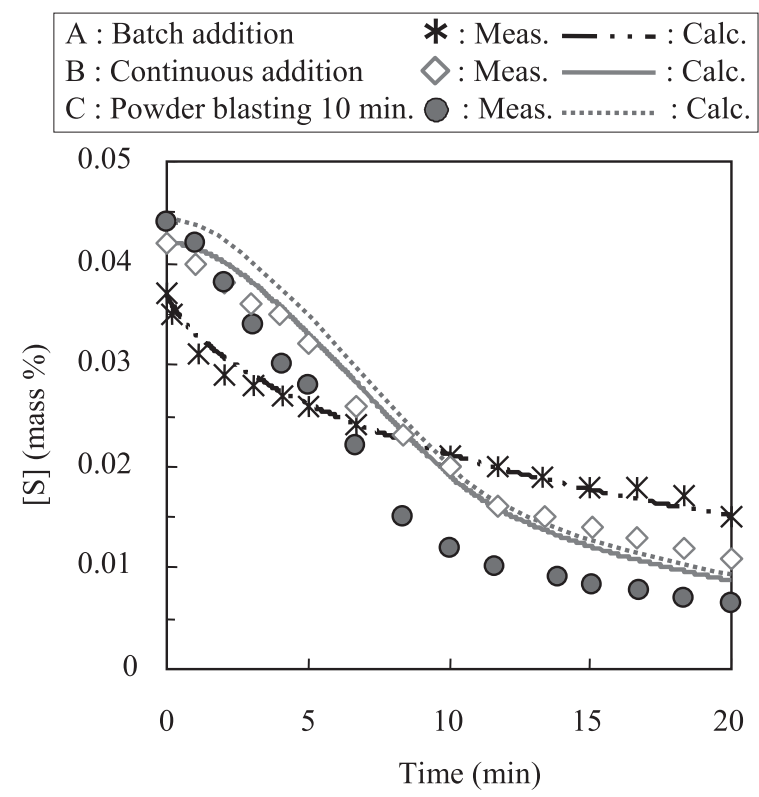

Fig. 12. Comparison between observed and calculated desulfurization behaviors (conditions A, B, and C).

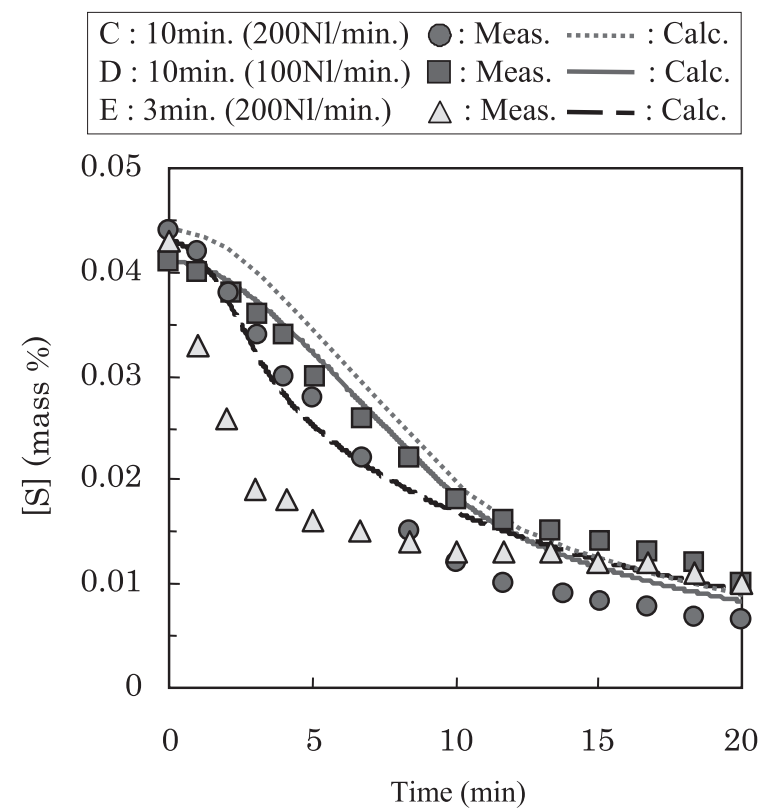

Fig. 13. Comparison between observed and calculated desulfurization behaviors under various powder blasting conditions (conditions $\mathrm{C}, \mathrm{D}$, and $\mathrm{E}$ ).

culated lines agreed with the observed data in Fig. 12. In case of condition A (batch addition), the reaction rate of [S] decreases with time because the particle diameter of the slag increases due to aggregation of the added flux with time and, as a result, the interfacial area decreases with time, as shown in Fig. 11.

In condition $\mathrm{B}$ (continuous addition), the desulfurization rate is low in the early stages of flux addition (about $3 \mathrm{~min}$ ) since the amount of added flux is small compared with condition A (batch addition). However, [S] after treatment in condition B is lower than in condition A (batch addition) because of the increased interfacial area due to the smaller particle diameter of the slag.

The behavior in which the measured desulfurization rate became low after $10 \mathrm{~min}$ is represented well by the increase

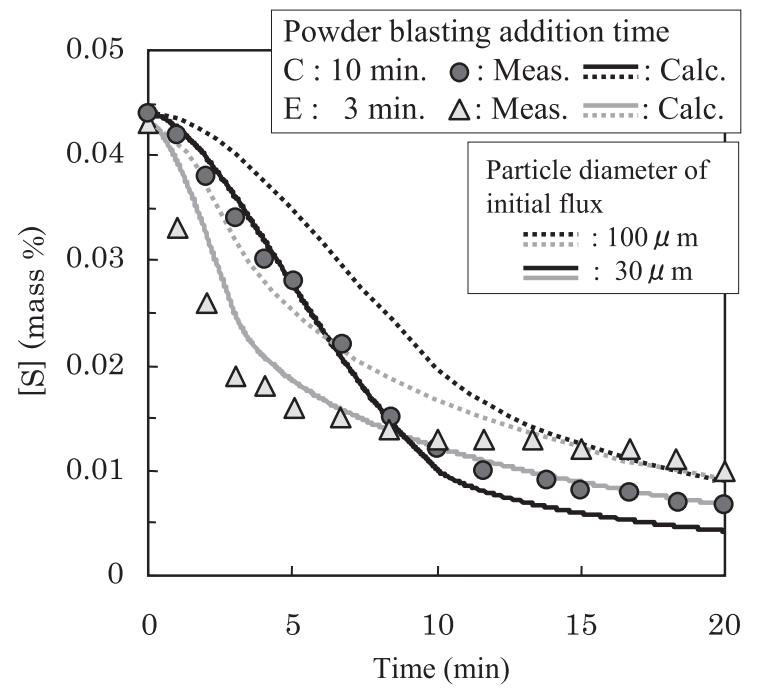

Fig. 14. Comparison between observed and calculated desulfurization behaviors (conditions $\mathrm{C}$ and $\mathrm{E}$ ).

in the particle diameter of the slag after flux addition (10 min), as shown in Fig. 11.

On the other hand, in condition $\mathrm{C}$ (powder blasting), the measured [S] is lower than the calculated value, and the deviation is especially large during the flux addition period.

From this observation, there is a possibility that the powder blasting method promotes not only the control of aggregation and an increase in the interfacial area by continuous addition, but also the desulfurization reaction itself under flux addition.

A comparison between the experimental values and the calculated values for the powder blasting conditions $(C, D$, and $\mathrm{E}$ ) is shown in Fig. 13. In condition $\mathrm{D}$, in which the nitrogen gas flow rate in top blowing was reduced to $100 \mathrm{Nl}$ / min, the calculated value showed good agreement with the experimental value. Since the nitrogen gas flow rate is low, it is considered that the specific effect of powder blasting on the desulfurization reaction is small, and only the effect of control of flux aggregation displays the same behavior as in condition $\mathrm{B}$ (continuous addition).

On the other hand, under conditions $\mathrm{C}$ and $\mathrm{E}$, in which the nitrogen gas flow rate for powder blasting was $200 \mathrm{Nl} / \mathrm{min}$, there are large deviations between the calculated value and the experimental value during flux addition time. In powder blasting with the nitrogen gas flow rate of $200 \mathrm{Nl} / \mathrm{min}$, it considered that flux with a small particle diameter penetrates directly into the molten metal without aggregation. As a result, the interfacial area increases, and this accelerates the desulfurization rate during flux addition time.

The experimental and calculated values were further investigated at different initial particle diameters. The results for conditions $\mathrm{C}$ and $\mathrm{E}$ are shown in Fig. 14. When the initial particle diameter of the flux was $30 \mu \mathrm{m}$, the calculated desulfurization value was in good agreement with the experimental value. The changes in the average particle diameter of the slag when the initial particle diameter of the flux was 100 or $30 \mu \mathrm{m}$ are shown in Fig. 15. The reduction of the particle diameter of the slag during flux addition time is remarkable.

In the case of powder blasting, in which the nitrogen gas flow rate in top blowing was $200 \mathrm{Nl} / \mathrm{min}$, when the 
initial particle diameter of the flux was assumed to be 30 $\mu \mathrm{m}$, the calculated value showed good agreement with the experimental value. Although the distribution of flux which penetrated into hot metal can not be experimentally confirmed, the present authors deem that smaller particle might penetrated at powder blasting compared to top addition on the bath surface. As the result, it is qualitatively suggested that the interfacial area between desulfurization flux and hot metal increased by powder blasting with high flow rate of nitrogen. Detailed analysis may be possible concerning alternative effects such as an improvement in mass transfer rate of sulfur in metal by agitation with powder blasting to

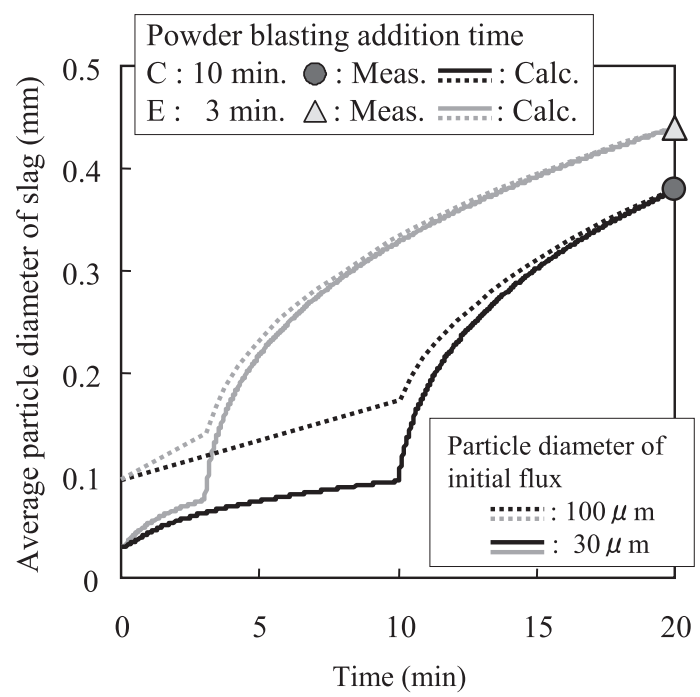

Fig. 15. Changes of average particle diameter of slag under various powder blasting conditions (conditions $\mathrm{C}$ and $\mathrm{E}$ ). estimate desulfurization behavior quantitatively. The present authors would like to consider this issue in a future research.

\subsection{Effect of Desulfurization Mechanism on Improve- ment of Desulfurization Efficiency by Powder Blasting}

From the above experimental results, the mechanism responsible for promoting desulfurization in powder blasting is considered. A schematic diagram of flux dispersion and aggregation behavior under various conditions is shown in Fig. 16, together with sulfur mapping images of the desulfurization slag after treatment. In all cases, sulfur is distributed at the surrounding edge of the slag particles in the sulfur mapping image of the slag after treatment.

Moreover, in continuous addition and powder blasting, the particle diameter of the slag is smaller than that in batch addition, as shown in Fig. 11. Small particles with sulfur distribution at the surrounding edge exist inside the aggregated slag. This fact suggests the possibility that the diameter of the aggregated slag was small in the early stages of flux addition. After treatment by powder blasting, many portions of the slag display high sulfur concentrations. It is considered that the small diameter initial flux reacts with sulfur at the time of flux addition and is trapped in the aggregated slag particles. On the other hand, it is thought that the flux added by batch addition aggregates when the flux is entrained in the hot metal, and this occurs before the flux can react sufficiently with sulfur.

In continuous addition of the flux, the flux addition rate is relatively low and aggregation of the added flux is controlled. In continuous addition and powder blasting, it is considered that the aggregation rate of the flux is low,

(a) Schematic diagram of dispersion and aggregation of flux

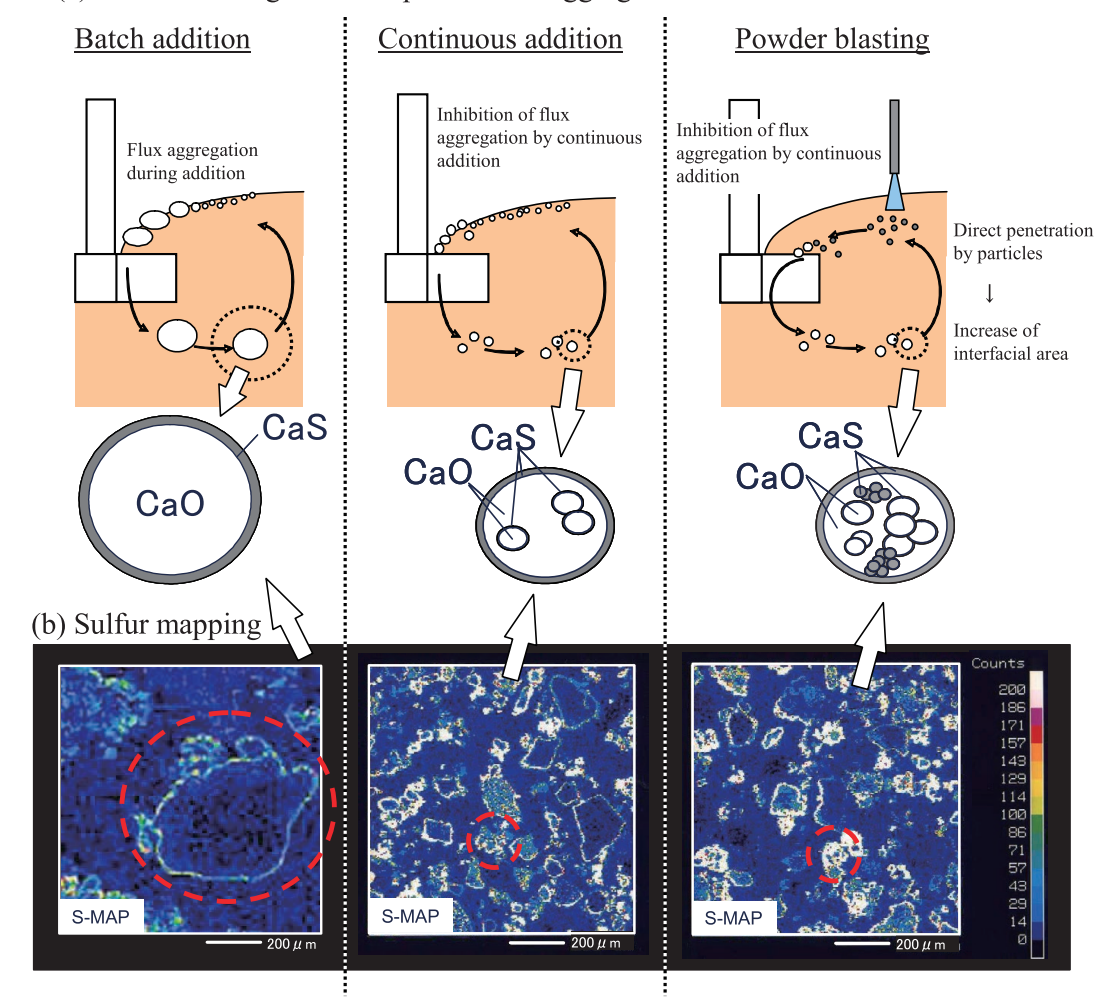

Fig. 16. (a) Schematic diagrams of flux dispersion and aggregation mechanisms and (b) Sulfur mappings in desulfurization slag after treatment. 
and as a result, the particle diameter of slag after treatment decreases. Furthermore, in powder blasting, some flux particles may penetrate directly into hot metal. In this case, the interfacial area between the flux and the hot metal would be large, and this would contribute to promoting desulfurization during flux addition time. Therefore, it is thought that the improvement of desulfurization efficiency by the powder blasting method depends on promotion of flux dispersion during flux addition and on control of flux aggregation by decreasing the amount of added flux per unit time by continuous addition.

\section{Conclusions}

The effects of three flux addition methods (batch, continuous, blasting) on hot metal desulfurization with mechanical stirring were investigated in a water model experiment and $70 \mathrm{~kg}$ hot metal desulfurization experiments. The conclusions are summarized as follows.

(1) Flux dispersion/aggregation behavior with impeller stirring was investigated using a water model. In the case of batch addition, flux aggregation was observed on the water surface, and large aggregated particles were seen in the water. In powder blasting, little particle aggregation was seen at the water surface for the flux particles penetrated directly into the water after flux addition, and the diameter of the aggregated particles was the smallest among the three methods.

(2) In the hot metal desulfurization experiments, the desulfurization rate was large in order of $\mathrm{C}$ : powder blasting $>$ $\mathrm{B}$ : continuous addition $>\mathrm{A}$ : batch addition. The average particle diameters of the slag after treatment by continuous addition and powder blasting were smaller than that in batch addition, and small particles with sulfur distributed at the surrounding edge existed inside the aggregated slag. This suggests the possibility that the diameter of the aggregated slag was small in the early stages of flux addition.

(3) The aggregation behavior with various flux addition methods was evaluated by using a flux aggregation model. In continuous addition and powder blasting, the aggregation rate constant was low compared with that in batch addition. The aggregation rate constant was almost the same under the various powder blasting conditions examined here. From this, it is presumed that the degree of aggregation depends on the addition method.

(4) The interfacial area between the flux and the hot metal was also estimated by using the aggregation model, which could be applied to estimate desulfurization behavior in continuous addition. The results proved the superiority of continuous addition in terms of interfacial area. High desulfurization efficiency was achieved in the powder blasting condition, where the flux was added over a longer time together with $200 \mathrm{Nl} / \mathrm{min}$ of nitrogen gas. When the initial flux particle diameter was $30 \mu \mathrm{m}$, the calculated desulfurization behavior showed good agreement with the experimental value.

(5) In hot metal desulfurization with mechanical stirring, desulfurization efficiency was improved by powder blasting. It is thought that the mechanism responsible for improvement of desulfurization efficiency with the powder blasting method depends on promotion of flux dispersion during flux addition and control of aggregation of the flux by decreasing the amount of added flux per unit time by continuous addition.

\section{Nomenclature}

A: Interfacial area $\left(\mathrm{m}^{2}\right)$

$D$ : Aggregated particle diameter (m)

$D_{a}:$ Average size $(\mathrm{mm})$

$D_{e}$ : Aggregated particle diameter in equilibrium state (m)

$D_{f}$ : Initial added particle diameter (flux diameter) (m)

$d_{i}$ : Particle size of slag $(\mathrm{mm})$

$K$ : Constant depend on condition of granulation (-)

$K_{S}$ : Apparent desulfurization rate constant $(1 / \mathrm{min})$

$k_{a}$ : Aggregation rate constant $\left(\mathrm{m}^{3} / \mathrm{s}\right)$

$k_{m}$ : Mass transfer rate $(\mathrm{m} / \mathrm{s})$

$n$ : Number of particles whose diameter is $\mathrm{D}(-)$

$\mathrm{r}$ : Radius of impeller $(\mathrm{m})$

[S]: Sulfur content in hot metal (mass\%)

t: Time (second)

$V_{f}$ : Flux volume $\left(\mathrm{m}^{3}\right)$

$V_{m}$ : Volume of particle-dispersed liquid (hot metal) $\left(\mathrm{m}^{3}\right)$

$W_{f}$ : Total weight of granulates (flux) $(\mathrm{kg})$

$W_{m}$ : Hot metal weight $(\mathrm{kg})$

$w_{i}$ : Weight of each size distribution $(\mathrm{kg})$

$\gamma$ : Number of particles in unit volume of liquid (-)

$\gamma_{e}$ : Number of particles in equilibrium state $(-)$

$\gamma_{f}$ : Initial number of particles (-)

$\varepsilon$ : Void ratio in aggregated particles $(-)$

$\rho_{f}$ : Particle (flux) density $\left(\mathrm{kg} / \mathrm{m}^{3}\right)$

$\rho_{m}$ : Liquid (hot metal) density $\left(\mathrm{kg} / \mathrm{m}^{3}\right)$

$\tau$ : Surface tension $(\mathrm{N} / \mathrm{m})$

$\omega$ : Angular velocity of impeller rotation $(\mathrm{rad} / \mathrm{s})$

\section{REFERENCES}

1) J. E. Ostberg: Giesserei, 53 (1966), 816.

2) F. Kraemer, J. Mots and K. Rohrig: Giesserei, 55 (1968), 145.

3) K. Kanbara, T. Nisugi, O. Shiraishi and T. Hatakeyama: Tetsu-toHagané, 58 (1972), 34.

4) K. Nakanishi, N. Bessyo, S. Takada, A. Ejima, M. Kuga, J. Katsuki and M. Kawana: Tetsu-to-Hagané, 64 (1978), 1528.

5) N. Kurokawa, S. Matsuo, H. Jouguchi, K. Yamada and Y. Watanabe: Sumitomo Met., 45 (1993), 52.

6) N. Kikuchi, S. Nabeshima, S. Takeuchi, T. Yamauchi, Y. Kitano and S. Ogura: Tetsu-to-Hagané, 90 (2004), 322.

7) N. Kikuchi, S. Nabeshima and Y. Kishimoto: ISIJ Int., 52 (2012), 1809.

8) Y. Nakai, I. Sumi, H. Matsuno, N. Kikuchi and Y. Kishimoto: ISIJ Int., 50 (2010), 403.

9) Y. Nakai, I. Sumi, N. Kikuchi, Y. Kishimoto and Y. Miki: ISIJ Int., 53 (2013), 1411.

10) M. Mizoguchi: Handbook of Powder Technol, 2nd ed., SPTJ, Nikkan Kogyo Shimbun, Tokyo, (1998), 8.

11) M. Koishi and M. Tsunoda: Surface Chemistry of Powder, 3rd ed., Nikkan Kogyo Shimbun, Tokyo, (1978), 188.

12) H. Takenaka, Y. Kawashima and M. Nakashima: J. Soc. Mater. Sci. Jpn., 28 (1979), 836.

13) C. E. Capes and J. P. Sutherland: Ind. Eng. Chem., 6 (1967), 146.

14) D. M. Newwitt and J. M. Conway-Jones: Trans. Inst. Chem. Eng., 36 (1958), 422.

15) M. Iwasa, Y. Hino, Y. Nakai, I. Sumi, N. Kikuchi, S. Nabeshima and Y. Kishimoto: 4th Int. Cong. on the Science and Technology of Steelmaking (ICS 2008), ISIJ, Tokyo, (2008), 288.

16) K. Nakanishi, A. Ejima, T. Suzuki and A. Sudo: Tetsu-to-Hagané, 64 (1978), 1323.

17) K. Narita, Y. Satoh, T. Mori, T. Ito and A. Kujime: Tetsu-to-Hagané, 62 (1976), 962.

18) H. Ooi, Y. Oguti and H. Minami: Tetsu-to-Hagané, 56 (1970), 991. 